\title{
Inhibition of HINI influenza virus-induced apoptosis by functionalized selenium nanoparticles with amantadine through ROS- mediated AKT signaling pathways
}

This article was published in the following Dove Press journal:

International Journal of Nanomedicine

\author{
Yinghua Li* \\ Zhengfang Lin* \\ Min Guo \\ Mingqi Zhao \\ Yu Xia \\ Changbing Wang \\ Tiantian Xu \\ Bing Zhu \\ Center Laboratory, Guangzhou \\ Women and Children's Medical \\ Center, Guangzhou Medical University, \\ Guangzhou, China
}

*These authors contributed equally to this work
Correspondence: Bing Zhu

Center Laboratory, Guangzhou

Women and Children's Medical Center,

Guangzhou Medical University, No 318

Renminzhong Road Yuexiu District,

Guangzhou 510120 , China

Tel +862081330740

$\mathrm{Fax}+862081885978$

Email zhubing2016@hotmail.com

\begin{abstract}
Introduction: As a therapeutic antiviral agent, the clinical application of amantadine (AM) is limited by the emergence of drug-resistant viruses. To overcome the drug-resistant viruses and meet the growing demand of clinical diagnosis, the use of biological nanoparticles (NPs) has increased in order to develop novel anti-influenza drugs. The antiviral activity of selenium NPs with low toxicity and excellent activities has attracted increasing attention for biomedical intervention in recent years.

Methods and results: In the present study, surface decoration of selenium NPs by AM (Se@,AM) was designed to reverse drug resistance caused by influenza virus infection. Se@ AM with less toxicity remarkably inhibited the ability of H1N1 influenza to infect host cells through suppression of the neuraminidase activity. Moreover, Se@AM could prevent H1N1 from infecting Madin Darby Canine Kidney cell line and causing cell apoptosis supported by DNA fragmentation and chromatin condensation. Furthermore, Se@AM obviously inhibited the generation of reactive oxygen species and activation of phosphorylation of AKT.

Conclusion: These results demonstrate that $\mathrm{Se} @ \mathrm{AM}$ is a potentially efficient antiviral pharmaceutical agent for H1N1 influenza virus.
\end{abstract}

Keywords: selenium nanoparticles, amantadine, influenza virus, apoptosis, nanodrug

\section{Introduction}

Influenza virus is a segmented RNA virus which is the most highly contagious pathogen worldwide and affects millions of people with influenza each year in seasonal epidemics. ${ }^{1,2}$ H1N1 influenza virus, which belongs to influenza A type viruses, is a highly infectious respiratory disease. ${ }^{3}$ This virus was discovered and identified in Mexico and the USA in 2009 and caused 8,768 deaths in 207 countries. ${ }^{4}$ The mode of spread of H1N1 influenza is as follows: sneezing, cough, and contaminated materials. ${ }^{5}$ Owing to the mutation of the genome and antigenic shifts in the emerging cross-species infection by avian influenza virus, the influenza virus has a high variability, which may lead to novel influenza strain among humans. ${ }^{6}$ The influenza infection cycle comprises of several steps: first, the influenza viruses attach to the host cell surface receptor and fuse with the endosomal membrane; second, uncoating of nucleocapsid and multiplication of the genetic material occurs; and finally, the influenza protein and new viron is expressed and released. ${ }^{7,8}$ Hemagglutinin (HA) and neuraminidase (NA) found on the surface of influenza virus are the most important glycoproteins. HA is a cell-anchoring viral glycoprotein which plays an important role in viral infection 
by combining sialic acid-containing receptors on host cells and mediating the entry and fusion of the virus..$^{9,10}$ NA plays an important role in assisting the virus to cleave the linkage between sialic acid and hemagglutinin. ${ }^{11}$

Existing antiviral drugs approved by the US Food and Drug Administration are NA inhibitors such as oseltamivir/ zanamivir and M2 ion channel inhibitors such as rimantadine/ amantadine (AM). ${ }^{12,13}$ The M2 proton channel is a critical factor in viral replication; the replication cycle is arrested and infection of the host is halted when proton transport through the channel is inhibited. ${ }^{14,15}$ The M2 protein is a 97-residue integral membrane protein with a TM domain of 19 residues and a 54-residue cytoplasmic tail, with several point mutations in pore-lining residues of the A/M2 TM domain resulting in resistance to AM. ${ }^{16,17}$ Because of the emergence of such drug resistance, AM and rimantadine are no longer recommended as common clinical anti-influenza treatments. ${ }^{18,19}$ Therefore, the antiviral therapies must be promoted in an attempt to control the pandemic influenza A virus.

Nanomaterials with unique chemical and physical properties have emerged as a promising alternative for virus control. ${ }^{20}$ The design of new antiviral nanodrug should consider strategies to effectively control viral infection and also deal with the cytotoxicity related to the exposure of biological materials. $^{21,22}$ According to Tao et al, consensus M2e peptide was combined with gold nanoparticles (NPs) against H1N1 influenza A viruses. ${ }^{23}$ According to Ye et al, graphene oxide is a promising antiviral agent due to its unique properties. ${ }^{24}$ According to Vonnemann et al, different sizes of polyvalent NPs inhibited virus. ${ }^{25}$ Meanwhile, the potential of NPs against viral infections through immunization was reported by Sokolova et al. ${ }^{26}$ Wang et al reported that the $\mathrm{SiO}_{2}$-layered double hydroxide NPs enhance the response of hepatitis B virus DNA vaccine. ${ }^{27}$ According to Wang et al, polyoxometalate with a broad spectrum may be a new type of antiviral agent. ${ }^{28}$ According to Barras et al, carbon nanodots have highefficiency functionality as entry inhibitors in the early stage of virus infection. ${ }^{29}$ According to Khanal et al, phenylboronicacid-modified NPs possess potential antiviral therapeutic application. ${ }^{30}$ Among them, selenium NPs (SeNPs) with their unique antimicrobial activities have attracted considerable attention. ${ }^{31,32} \mathrm{Se}$ is an essential nutritional trace element with the ability to regulate cellular redox homeostasis. ${ }^{33-35}$ The deficiency of Se could increase the susceptibility to infections, including respiratory virus and hepatitis B virus infections. ${ }^{36,37}$ In this study, we present novel SeNPs that can inhibit the ability of H1N1 influenza virus to infect host cell. We look forward to verifying that AM-modified SeNPs (Se@,AM) have excellent antiviral activity. Reactive oxygen species (ROS) plays an important role in many physiological processes; oxidative stress is explicated between consumption of ROS and cellular defense mechanisms. ${ }^{38,39}$ The imbalance of redox is associated with many pathologies, such as skin disease, diabetes, cancer, Leigh syndrome and other diseases. ${ }^{40}$ This study was performed to investigate how Se@AM inhibits H1N1 influenza virus-induced host cells apoptosis through ROS-mediated signaling pathways.

\section{Materials and methods Materials}

The Madin-Darby Canine Kidney (MDCK) cells were obtained from ATCC ${ }^{\circledR}$ CCL-34TM. H1N1 influenza virus was provided by the Virus Laboratory, Guangzhou Women and Children's Medical Center, Guangzhou Medical University. Fetal bovine serum and DMEM were purchased from Thermo Fisher Scientific, Waltham, MA, USA. $\mathrm{Na}_{2} \mathrm{SeO}_{3}$, vitamin C, AM, MTT, propidium iodide, 4',6-diamidino-2phenylindole (DAPI), and 2', $7^{\prime}$-dichlorofluorescin (DCF)diacetate were purchased from Sigma-Aldrich Co. (St Louis, MO, USA). AKT and caspase-3 antibodies were purchased from Cell Signaling Technology (Boston, MA, USA).

\section{Preparation of Se@AM}

SeNPs were synthesized as follows: $0.25 \mathrm{~mL}$ stock solution $(0.1 \mathrm{M})$ of $\mathrm{Na}_{2} \mathrm{SeO}_{3}$ was gradually added to $2 \mathrm{~mL}$ stock solution $(50 \mathrm{mM})$ of vitamin $\mathrm{C}$. Then, $0.8 \mathrm{~mL}$ of $1 \mu \mathrm{M}$ AM was added to the SeNPs solution. We detected the excess AM, vitamin and $\mathrm{Na}_{2} \mathrm{SeO}_{3}$ by dialysis for 24 hours. $\mathrm{Se} @$ AM NPs were sonicated and then filtered through $0.2 \mu \mathrm{m}$ size pores. The concentration of SeNPs and AM was measured by inductively coupled plasma atomic emission spectroscopy.

\section{Characterization of Se@AM}

The morphology of Se@AM NPs was characterized by transmission electron microscopy (TEM, H-7650). Elemental composition of Se@AM was determined by energy dispersive X-ray spectroscopy (EDX) (EX-250 system; Horiba, Kyoto, Japan).Zeta potential and size distribution of Se@AM were monitored by Malvern Zetasizer (Malvern Instruments Limited, Manchester, UK) software. Fourier-transform infrared spectroscopy samples were recorded using the potassium bromide-disk method (Equinox 55 IR spectrometer). X-ray photoelectron spectroscopy (XPS) measurement was carried out on ESCALab 250 spectrometer. ${ }^{41}$

\section{Cell viability by MTT assay}

Cytotoxicity of Se@AM NPs was performed as previously described..$^{42} \mathrm{H} 1 \mathrm{~N} 1$ influenza virus was incubated for $2 \mathrm{~h}$ and 
then rinsed to remove the viruses that were not internalized. The indicated concentrations of AM with or without SeNPs were added to MDCK cells for $24 \mathrm{~h}$. Then, $20 \mu \mathrm{L} /$ well MTT was added and incubated for $5 \mathrm{~h}$. The formazan crystals were dissolved by adding dimethyl sulfoxide (150 $\mu \mathrm{L} /$ well $)$ and measured at $570 \mathrm{~nm}$.

\section{TEM of Se@AM-treated HINI}

H1N1 influenza virus was treated with Se@AM, and then attached to the carbon-coated collodion grid. The grids were examined by TEM. $^{43}$

\section{The NA inhibition assay by Se@AM}

MDCK cells were infected with H1N1 influenza virus for $2 \mathrm{~h}$. After $24 \mathrm{~h}$, the cell culture supernatants were harvested. Influenza virus NA activity was determined by quantifying the fluorescent product resulting from the cleavage of the substrate 4-methylumbelliferyl- $\alpha-\mathrm{D}-N$-acetylneur-aminic acid sodium salt hydrate solution by NA. ${ }^{44}$ The reaction mixture consisted of the tested compounds, after incubation for $30 \mathrm{~min}$ at $37^{\circ} \mathrm{C}$. The fluorescence of the mixture was recorded at excitation wavelength of $360 \mathrm{~nm}$ and emission at $460 \mathrm{~nm}$.

\section{Detection of mitochondrial membrane potential $(\Delta \Psi \mathrm{m})$}

The fluorescence intensity from JC-1 monomers was used to estimate the status of $\Delta \Psi \mathrm{m}$ in MDCK cells exposed to Se@oseltamivir (OTV), as previously described. ${ }^{45}$ Cells were trypsinized and resuspended with $10 \mu \mathrm{g} / \mathrm{mL}$ of JC-1. The MDCK cells were then harvested and analyzed by flow cytometry.

\section{Annexin-V-FLUOS staining assay}

Plasma membrane alterations in MDCK cells treated with Se@AM were detected as previously described. ${ }^{46}$ Briefly, MDCK cells were treated with Se@AM for 24 h and stained with annexin-V-FLUOS, then washed with PBS 3 times, and observed by flow cytometric analysis.

\section{Terminal deoxynucleotidyl transferase- mediated deoxyuridine triphosphate nick-end labeling (TUNEL)-DAPI co-staining assay}

MDCK cells were observed under fluorescence microscope with TUNEL and incubated with DAPI for nuclear staining, as previously described. ${ }^{47}$

\section{Caspase-3 activity}

The caspase- 3 activity was detected under fluorescence microscope with the excitation at $380 \mathrm{~nm}$ and emission at $460 \mathrm{~nm}$ wavelengths, as previously described. ${ }^{48}$

\section{TEM analysis of thin sections of MDCK cells}

TEM analysis of MDCK cells was performed in situ as previously described. ${ }^{49}$

\section{Determination of ROS generation}

The ROS level was monitored by analyzing the fluorescence intensity of DCF with excitation at $500 \mathrm{~nm}$ and emission at $529 \mathrm{~nm}$ wavelengths. ${ }^{50}$

\section{Western blotting analysis}

The total proteins were obtained after MDCK cells were treated with Se@AM and incubated with lysis buffer. BCA assay was used to quantify the protein concentration. The bolts were developed with enhanced chemiluminescence reagent that examines the target proteins on the X-ray film. ${ }^{51}$

\section{Statistical analysis}

All the data are presented as mean \pm SD. Differences between the 2 groups were evaluated using 2-tailed Student's $t$-test. One-way analysis of variance was used in multiple-group comparisons. Difference with $P<0.05$ or $P<0.01$ was considered statistically significant.

\section{Results and discussion Preparation of Se@AM}

Functionalized Se@AM was synthesized. SeNPs were modified with AM to form more compact and stable NPs (Scheme 1). Light images of AM, SeNPs, and Se@AM are shown in Figure 1A. As shown in Figure 1B and C, the Tyndall effect of Se@AM indicated that Se@AM NPs were synthesized. The morphology of Se@AM presented

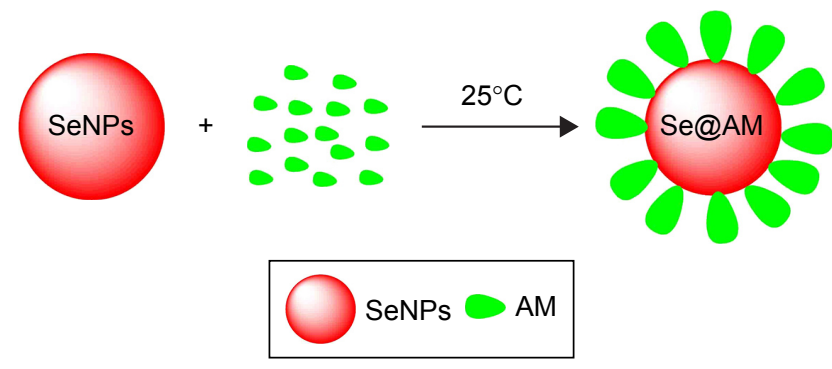

Scheme I Synthetic route toward Se@AM.

Abbreviations: AM, amantadine; Se@AM, AM-modified SeNPs; SeNPs, selenium nanoparticles. 

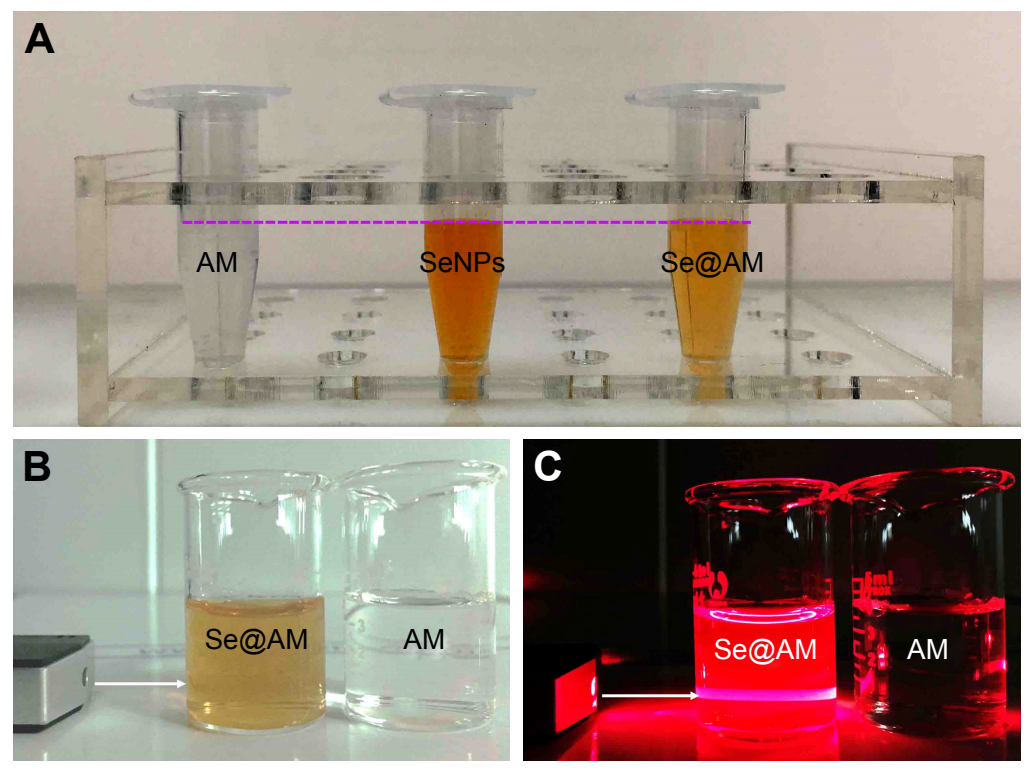

Figure I Light images of AM, SeNPs, and Se@AM.

Notes: (A) The color change of AM, SeNPs, and Se@AM. (B and C) Tyndall effect of Se@AM.

Abbreviations: AM, amantadine; Se@AM, AM-modified SeNPs; SeNPs, selenium nanoparticles.

A
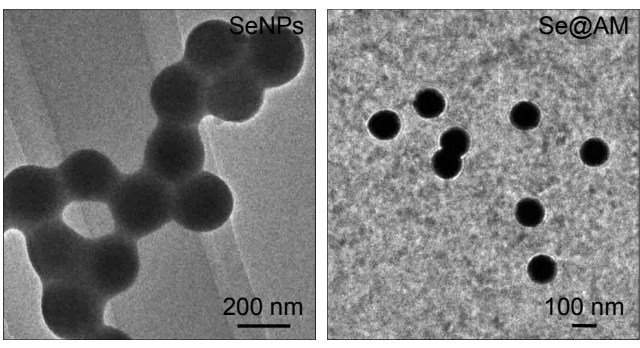

C

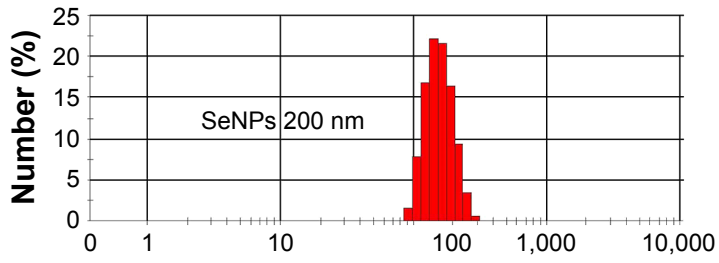

E

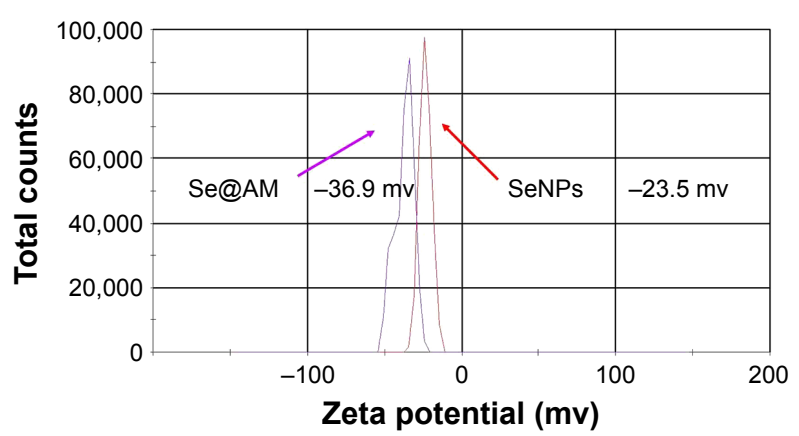

B

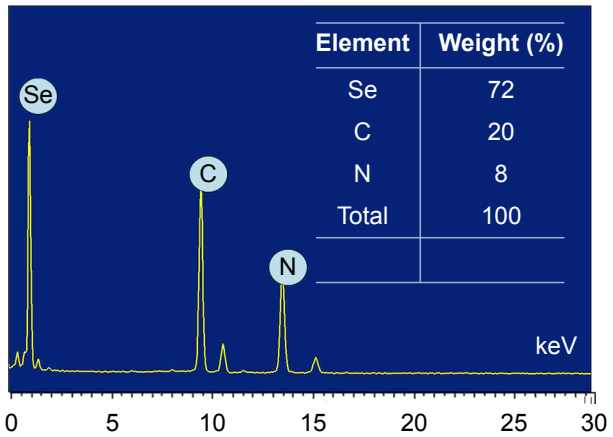

D
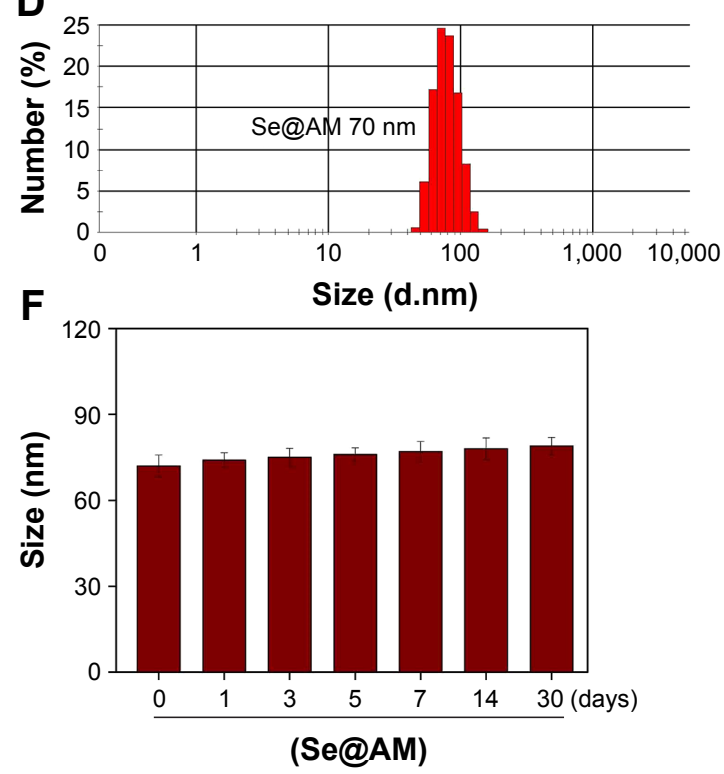

Figure 2 Characterizations of SeNPs and Se@AM.

Notes: (A) TEM images of SeNPs and Se@AM. (B) EDX analysis of Se@AM. (C and D) Size distribution of SeNPs and Se@AM. (E) Zeta potentials of SeNPs and Se@AM. (F) Stability of Se@AM in aqueous solutions.

Abbreviations: AM, amantadine; EDX, energy dispersive X-ray spectroscopy; Se@AM, AM-modified SeNPs; SeNPs, selenium nanoparticles; TEM, transmission electron microscopy. 
uniformly spherical particles as shown in Figure $2 \mathrm{~A}$. As shown in Figure 2B, EDX indicated the signal of C (20\%) and N (8\%) from AM, while Se atoms were $72 \%$. The size of Se@AM was decreased from 200 to 70 nm, which indicated much smaller size as shown in Figure 2C and D. The zeta potential of Se@AM (-36.9 mv)was lower than SeNPs $(-23.5 \mathrm{mv})$, demonstrating the higher stability of Se@AM than SeNPs as shown in Figure 2E. The size distribution of Se@AM in Figure 2F revealed that Se@AM was stable for 30 days.Se@AM was further characterized to confirm the chemical binding of AM to the surface of SeNPs. The Fourier transform infrared (FTIR) spectra of unmodified AM, SeNPs, and Se@AM are shown in Figure 3A. The FTIR spectrum of Se@AM resembles that of AM, giving clear evidence that AM ligand forms a part of the nanocomposite. AM displays IR absorbance peaks at 2,903, 1,264, and $739 \mathrm{~cm}^{-1}$ corresponding to $-\mathrm{CH}_{2},-\mathrm{NH}_{2}$, and $\mathrm{C}-\mathrm{N}$. The absence of these peaks in Se@AM indicated the formation of Se@AM. The XPS spectra were also recorded to examine the interaction between AM and SeNPs. As shown in Figure 3B, the N 1s peak in the spectrum of Se@AM further confirmed that AM has been successfully conjugated to the SeNPs.
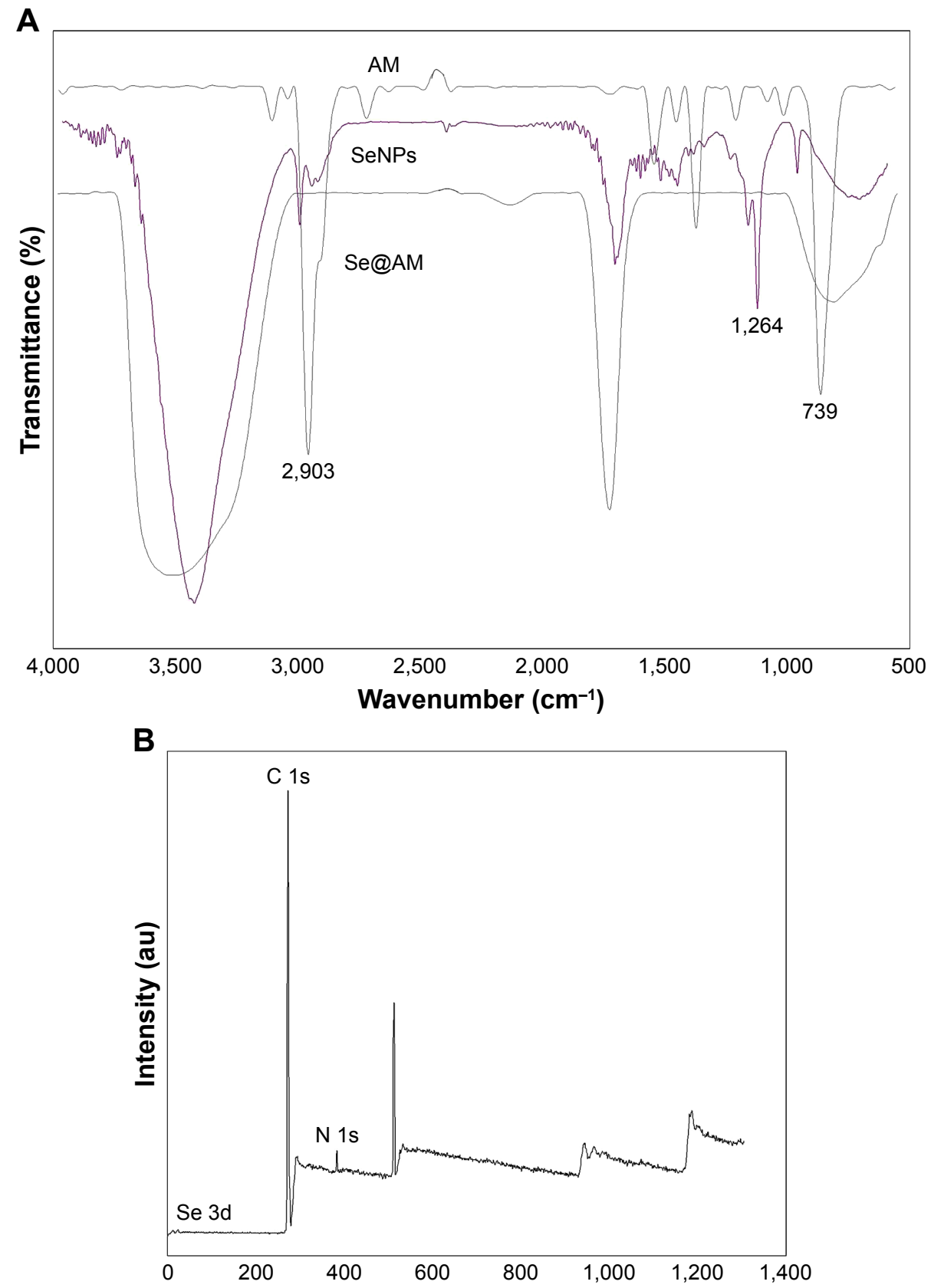

Figure 3 The FTIR spectra and XPS of Se@AM.

Notes: All IR spectra were acquired in the form of potassium bromide plates. (A) FTIR spectrums. (B) XPS detection.

Abbreviations: AM, amantadine; FTIR, Fourier transform infrared; Se@AM, AM-modified SeNPs; SeNPs, selenium nanoparticles; XPS, X-ray photoelectron spectroscopy. 


\section{A}
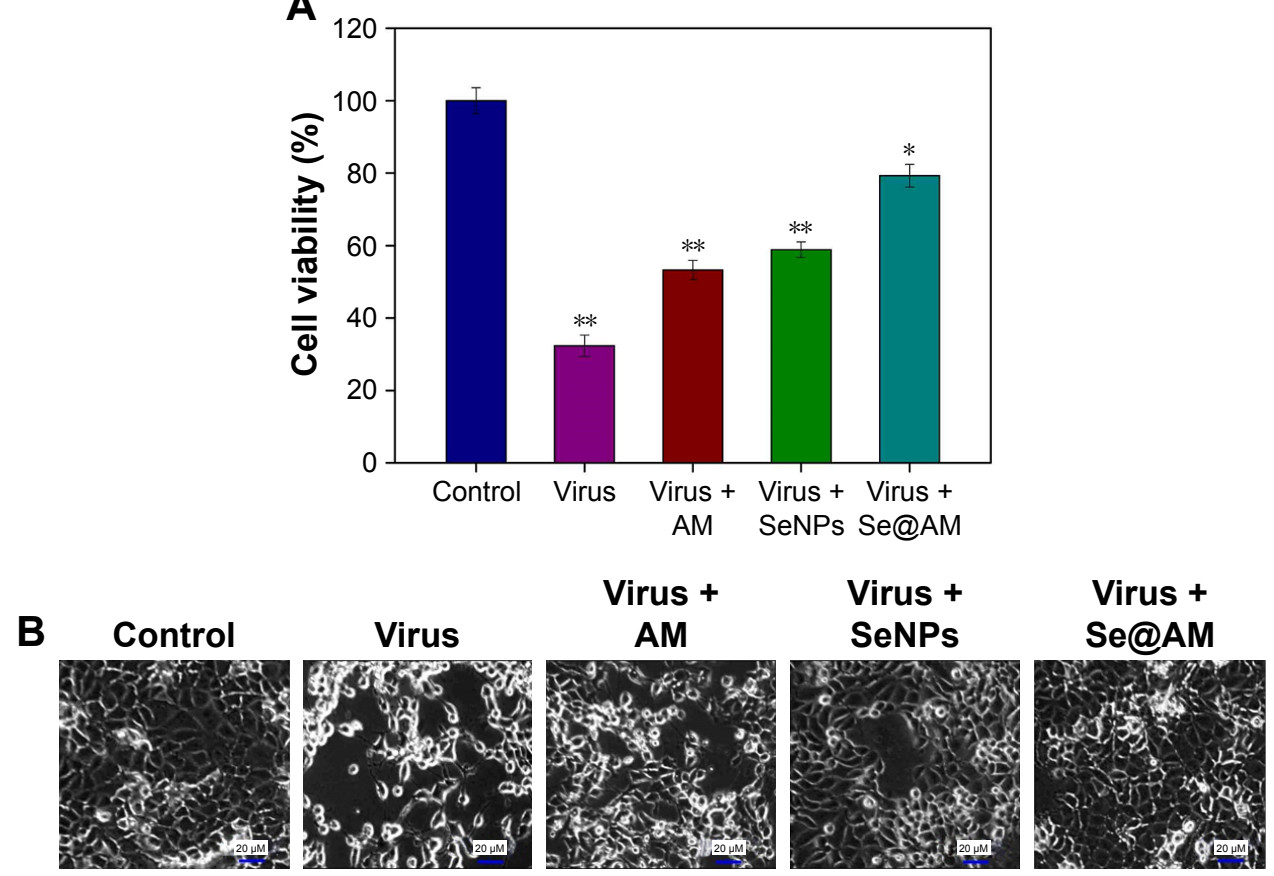

Figure 4 Effects of Se@AM on the growth of HINI infection of MDCK cells by MTT assay.

Notes: (A) Antiviral activity of Se@AM. Free concentration of SeNPs was I mM and AM $0.4 \mu \mathrm{m}$. AM (0.1 $\mu$ M) and SeNPs (0.125 $\mu$ M) were loaded onto the Se@AM. (B) Morphological changes in HINI-infected MDCK cells were observed by phase-contrast microscopy. Bars with different characters are statistically different at $* p<0.05$ or $* * p<0.0$ I level.

Abbreviations: AM, amantadine; MDCK, Madin-Darby Canine Kidney; Se@AM, AM-modified SeNPs; SeNPs, selenium nanoparticles.

\section{In vitro antiviral activity of Se@AM}

MDCK cells treated with H1N1 influenza virus showed cell viability of $32.34 \%$. AM and SeNPs increased the cell viability to $53.23 \%$ and $58.87 \%$, as shown in Figure $4 \mathrm{~A}$, but the cell viability of $\mathrm{Se} @ \mathrm{AM}$ was significantly increased to 79.26\%. The results indicate that the antiviral effect of Se@ AM was superior to that of free SeNPs and AM. As shown in Figure 4B, cells treated with H1N1 influenza virus showed cytoplasmic shrinkage, loss of cell-to-cell contract, and reduction in cells numbers. The MDCK cell morphology changed only slightly by co-treatment with Se@AM and appeared healthy in shape. Synergy was evaluated by calculation of in vitro fractional inhibitory concentration-index values: minimum inhibitory concentration (MIC) of Se in Se@AM $(125 \mu \mathrm{M})$; MIC of drug B combination concentration of AM in $\mathrm{Se} @ \mathrm{AM}(0.1 \mu \mathrm{M})$; MIC of drug A alone corresponded to free SeNPs $(1 \mathrm{mM})$; MIC of drug B alone corresponded to free AM $(0.4 \mu \mathrm{M})$. Fractional inhibitory concentration (FIC) was calculated as (MIC of drug A combination/MIC of drug A alone $)+($ MIC of drug B combination/MIC of drug B alone $)=125 \mu \mathrm{M} / 1 \mathrm{mM}+0.1 \mu \mathrm{M} / 0.4 \mu \mathrm{M}=0.375$. FIC was 0.375 , below 0.5 , indicating synergy. In this study, the FIC index was basically interpreted as follows: $\mathrm{FIC}<0.5$, synergy; FIC between 0.5 and 2, indifference; FIC $>2$, antagonism.
The results suggest that $\mathrm{Se} @ \mathrm{AM}$ effectively inhibited the proliferation of H1N1 influenza virus (Table 1). The titer of H1N1 was detected by Reed-Muench assay (TCID $\left.=10^{3.5}\right)$.

\section{HINI morphologic changes}

The group of H1N1 virus showed typical elliptical or spherically shaped normal H1N1 virus containing virus matrix and capsid (Figure 5A). After interaction of Se@AM with H1N1 virus for 12 and $24 \mathrm{~h}$, the parts of H1N1 viral edges were lost and the viral morphology was destroyed (Figure 5B and C). The results demonstrate that Se@AM could directly interact with virus particles and lead to disruption of viral function.

Table I Titer of HINI

\begin{tabular}{|c|c|c|c|c|c|}
\hline \multirow{2}{*}{$\begin{array}{l}\text { Dilution } \\
\text { of HIN I }\end{array}$} & \multirow{2}{*}{$\begin{array}{l}\text { CPE } \\
\text { (wells) }\end{array}$} & \multirow{2}{*}{$\begin{array}{l}\text { No CPE } \\
\text { (wells) }\end{array}$} & \multicolumn{2}{|c|}{ Accumulation } & \multirow{2}{*}{$\begin{array}{l}\text { Ratio of } \\
\text { CPE (\%) }\end{array}$} \\
\hline & & & $\begin{array}{l}\text { CPE } \\
\text { (wells) }\end{array}$ & $\begin{array}{l}\text { No CPE } \\
\text { (wells) }\end{array}$ & \\
\hline $10^{-1}$ & 8 & 0 & 24 & 0 & $100(24 / 24)$ \\
\hline $10^{-2}$ & 8 & 0 & 16 & 0 & $100(16 / 16)$ \\
\hline $10^{-3}$ & 5 & 3 & 8 & 3 & $72.7(8 / 11)$ \\
\hline $10^{-4}$ & 3 & 5 & 3 & 8 & $27.3(3 / 11)$ \\
\hline $10^{-5}$ & 0 & 8 & 0 & 16 & $0(0 / 16)$ \\
\hline
\end{tabular}

Notes: The Reed-Muench assay was used to test the titer of HINI (TCID50 $=10^{3.5}$ ). Abbreviations: CPE, cytopathic effect; TCID, tissue culture infective dose. 

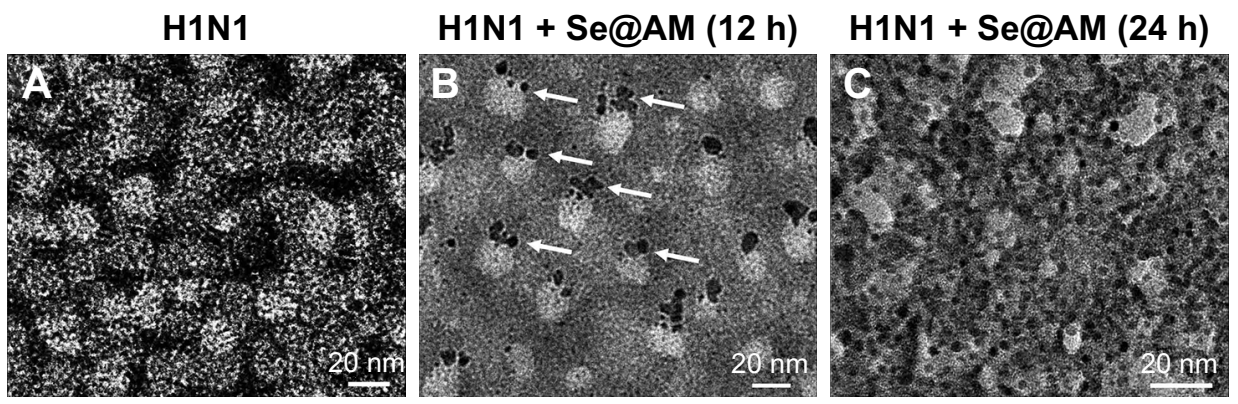

Figure 5 Morphologic abnormalities in Se@AM-treated HINI.

Notes: (A) The HR-TEM negative staining. (B and C) HINI virus interacting with Se@AM at I2 and 24 h. White arrows indicate the Se@AM nanoparticles. Abbreviations: AM, amantadine; HR, high resolution; Se@AM, AM-modified SeNPs; SeNPs, selenium nanoparticles; TEM, transmission electron microscopy.

\section{Identifying NA as the potential target of Se@AM}

Surface glycoprotein NA plays an important role in the entry of virus. Untreated H1N1 (100\%) or Se@AM-treated H1N1were used to measure the NA enzymatic activity. Compared with AM (75\%) and SeNPs (60\%), Se@AM (36\%) inhibited obvious enzymatic activity of influenza H1N1 viral NA, indicating that the Se@AM NPs had inhibitory effect on NA activity (Figure 6). The anti-influenza mechanism of $\mathrm{Se} @ \mathrm{AM}$ is postulated as: the $\mathrm{Se} @ \mathrm{AM}$ nanoparticles bind tightly to the NA protein, thus forbidding the attachment of H1N1 virus to MDCK cells.

\section{Depletion of mitochondrial membrane potential $(\Delta \Psi \mathrm{m})$ and translocation of phosphatidylserine induced by Se@OTV}

MDCK cells were treated with mitochondrial-selective JC-1 dye. As shown in Figure 7A, treatments of MDCK cells

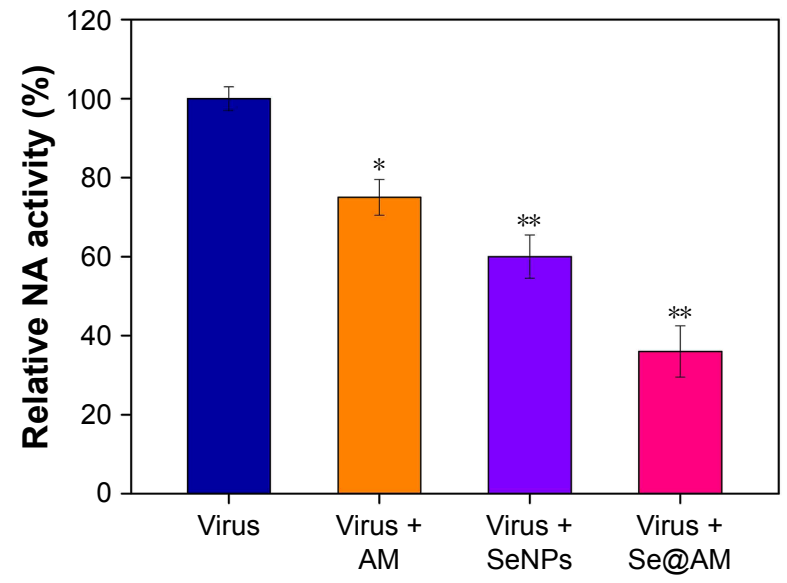

Figure 6 Inhibition of NA activity by Se@AM in HINI infection of cells. Notes: The NA inhibition assay was performed using a microplate reader. Bars with different characters are statistically different at $* p<0.05$ or $* * p<0.01$ level. Abbreviations: AM, amantadine; NA, neuraminidase; Se@AM, AM-modified SeNPs; SeNPs, selenium nanoparticles. with H1N1 influenza virus (30\%) resulted in elevation of mitochondrial depolarization and dysfunction. Compared with AM (55\%) and SeNPs (65\%), when MDCK cells were exposed to Se@AM, the percentage of mitochondrial membrane potential significantly increased to $85 \%$. These results demonstrate that Se@AM inhibited H1N1 influenza virus by apoptosis in MDCK cells by inducing mitochondrial dysfunction. The percentage of living cells treatment with H1N1 influenza virus was $48.80 \%$ as shown in Figure 7B. Compared with AM (66.98\%) and SeNPs (59.14\%), when MDCK cells were exposed to Se@AM, the percentage of MDCK cells treated with Se@AM revealed a decrease in cell number (79.96\%). The results demonstrate that Se@, AM restrained H1N1 virus infection of MDCK cells mainly through inhibiting apoptosis.

\section{Inhibition of HINI infection}

As shown in Figure 8, MDCK cells exhibited apoptotic features by H1N1 influenza virus with DNA fragmentation and nuclear condensation. Co-treatment with Se@AM remarkably prevented the H1N1 influenza virus-induced changes in nuclear morphology. The results indicate that Se@AM rescues the apoptosis of MDCK cells by H1N1 influenza virus.

\section{Inhibition of caspase- 3 activation}

Caspase-3 activity was used to determine cell apoptosis. As shown in Figure 9, treatment of MDCK cells with H1N1 obviously increased the caspase- 3 activity to $519.7 \%$. The caspase- 3 activity by AM and SeNPs was $483.6 \%$ and 428.3\%, respectively. However, Se@AM significantly decreased the caspase-3 activity to $290.2 \%$. The results show that the Se@AM inhibits H1N1 influenza virus activity.

\section{TEM image of thin sections of cells}

Mitochondria and microvilli were observed, with no morphological changes in untreated cells as shown in Figure 10A. 
A
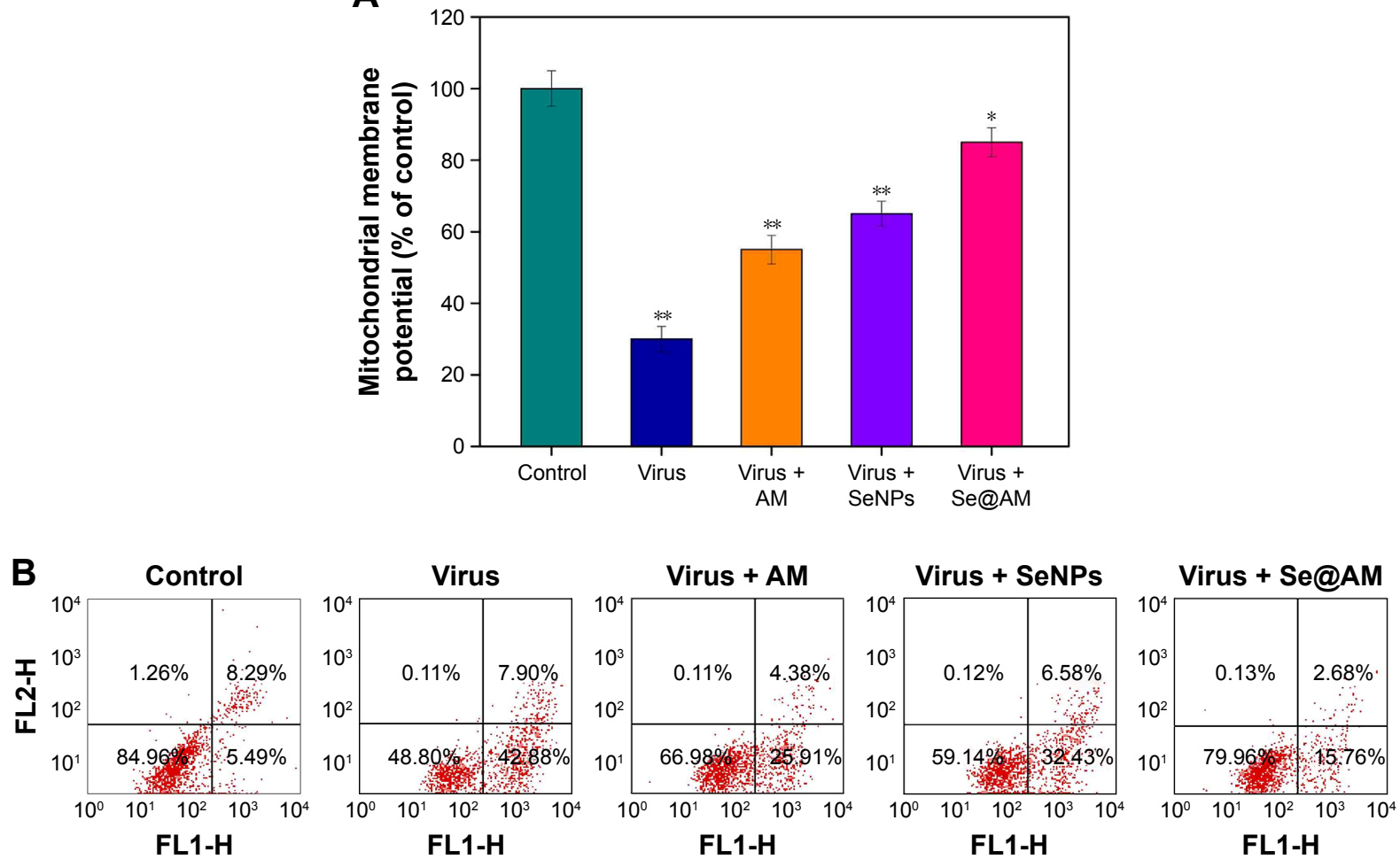

Figure 7 Depletion of mitochondrial membrane potential and translocation of phosphatidylserine induced by virus, AM, SeNPs, and Se@AM.

Notes: (A) Mitochondrial membrane potential of HINI infection of MDCK cells exposed to virus, AM, SeNPs, and Se@AM. (B) Translocation of phosphatidylserine induced by virus, AM, SeNPs and Se@AM in HINI infection of MDCK cells as determined by annexin-V-FLUOS labeling assay. Bars with different characters are statistically different at $P<0.05(*)$ or $P<0.01$ (**) level.

Abbreviations: AM, amantadine; MDCK, Madin-Darby Canine Kidney; NA, neuraminidase; Se@AM, AM-modified SeNPs; SeNPs, selenium nanoparticles.
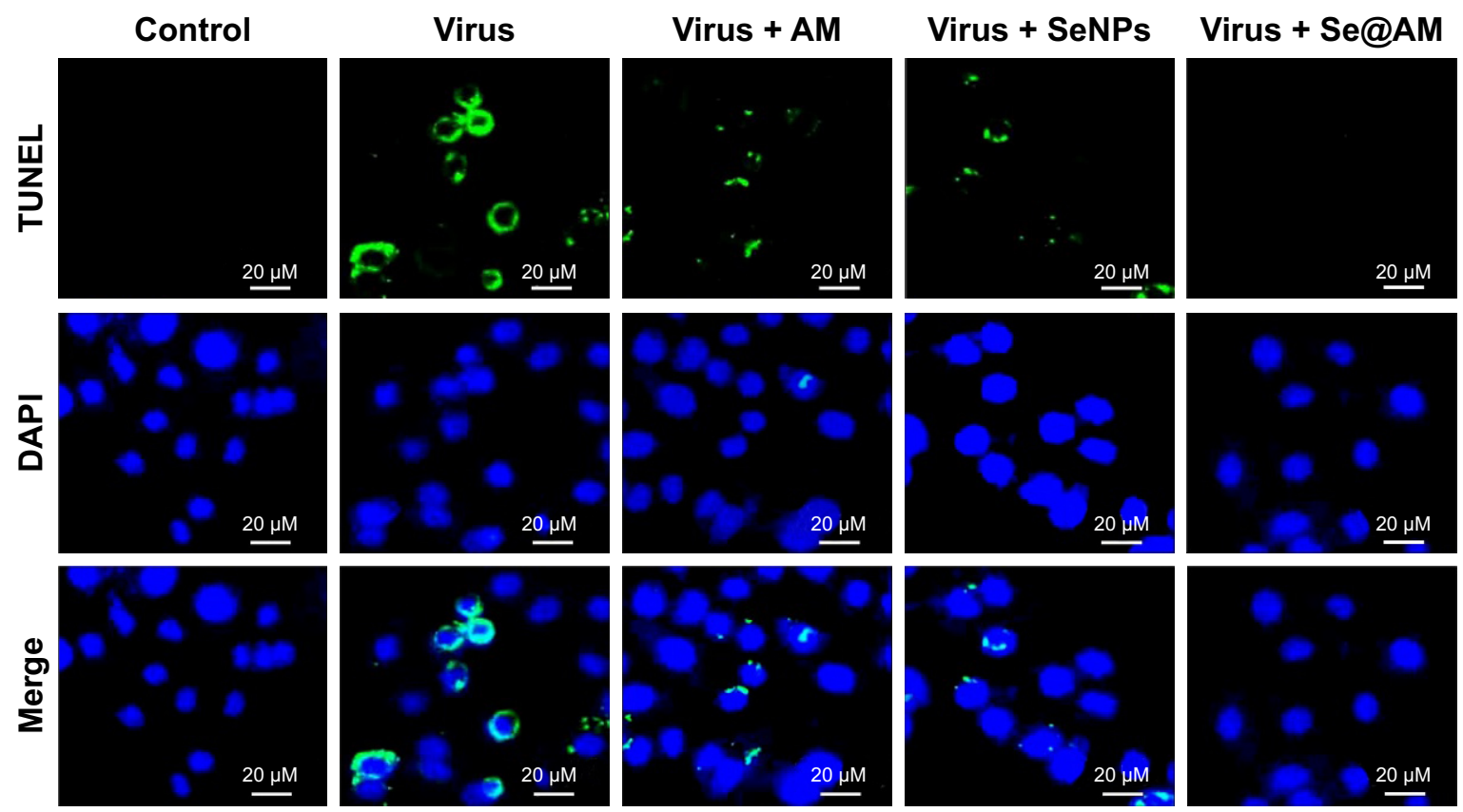

Figure 8 Se@AM inhibited apoptosis in HINI infection of MDCK cells.

Notes: DNA fragmentation and nuclear condensation as detected by TUNEL-DAPI co-staining assay. All results are representative of 3 independent experiments.

Abbreviations: AM, amantadine; DAPI, 4',6-diamidino-2-phenylindole; MDCK, Madin-Darby Canine Kidney; Se@AM, AM-modified SeNPs; SeNPs, selenium nanoparticles; TUNEL, terminal deoxynucleotidyl transferase-mediated deoxyuridine triphosphate nick-end labeling. 


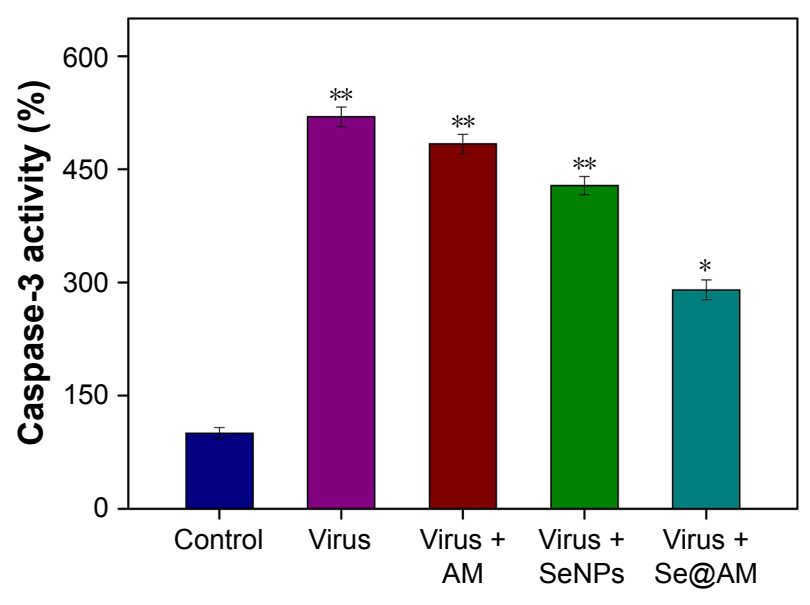

Figure 9 Inhibition of caspase-3 activity by Se@AM in HINI infection of cells. Notes: Cells were treated with Se@AM and caspase-3 activity detected by synthetic fluorogenic substrate. Bars with different characters are statistically different at $* p<0.05$ or $* * p<0.0$ l level.

Abbreviations: AM, amantadine; Se@AM, AM-modified SeNPs; SeNPs, selenium nanoparticles.

When MDCK cells were treated with H1N1 influenza virus, TEM image indicated distorted organelles and condensed chromatin, which indicated apoptosis of MDCK cells (Figure 10B). As shown in Figure 10C, the mitochondria of MDCK cells recovered their shape after treatment with Se@AM, which could reveal that H1N1 influenza virus induced apoptosis.

\section{Inhibition of ROS generation by Se@AM}

The ROS generation was monitored through DCF assay to indicate the action mechanisms of Se@AM. As shown in Figure 11A, the ROS generation by H1N1 influenza virus was increased to $420 \%$. AM and SeNPs slightly inhibited the ROS generation to $280 \%$ and $230 \%$. However, Se@AM remarkably decreased the rate of ROS generation (130\%).
The fluorescent intensity of DCF was found by H1N1 influenza virus as shown in Figure 11B. The fluorescent intensity of DCF in MDCK cells treated with H1N1 influenza virus was much stronger than in those treated with $\mathrm{Se} @ \mathrm{AM}$. These results show that $\mathrm{Se} @ \mathrm{AM}$ could downregulate the level of ROS in the antiviral action.

\section{ROS activates apoptotic signaling pathways by Se@AM}

The over-generation of ROS could cause DNA damage and affect the regulation of apoptosis signaling pathways. Compared with AM and SeNPs, treatments of MDCK cells with $\mathrm{Se} @$ AM remarkably inhibited the expression levels of caspase-3, as shown in Figure 12A. Meanwhile, the level of AKT was significantly increased by Se@AM (Figure 12B). Taken together, Se@AM depressed H1N1 influenza virus-induced host cell apoptosis by ROS-mediated AKT signaling pathways (Figure 12C).

\section{Conclusion}

In summary, an efficient chemical method for AM surfacemodified SeNPs was described in this study. Se@AM with lower toxicity exhibits enhanced abilities to prevent H1N1 influenza virus infection. The NA activity of H1N1 influenza virus was inhibited by Se@AM. The molecular mechanisms demonstrated that $\mathrm{Se} @$ AM inhibited caspase-3 activity and mediated apoptosis through ROS generation. Furthermore, Se@AM inhibited MDCK cell apoptosis by decreasing the level of ROS to trigger AKT pathways. Therefore, Se@AM might provide a promising Se subtype with antiviral properties against $\mathrm{H} 1 \mathrm{~N} 1$ influenza virus.
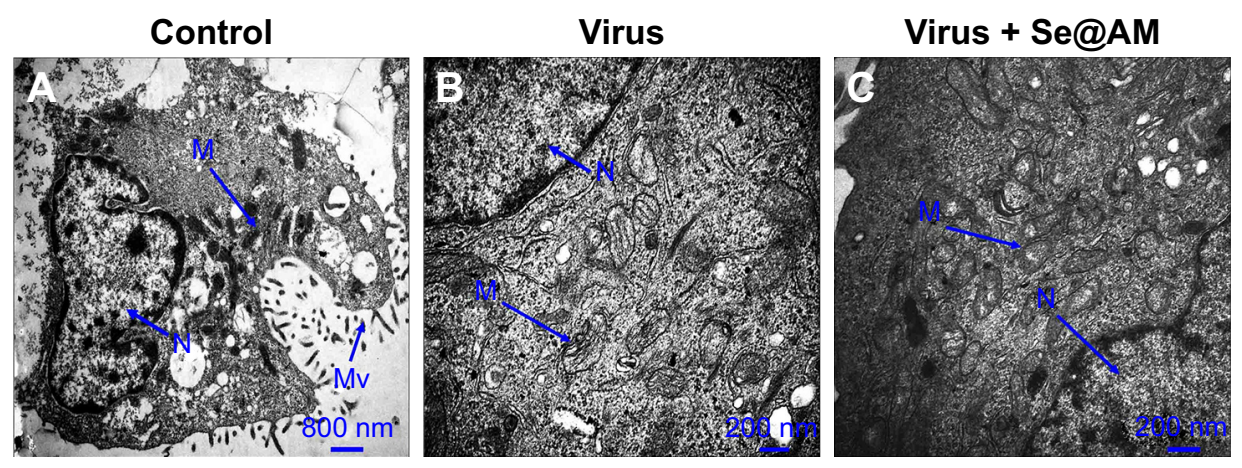

Figure 10 TEM images of thin sections of MDCK cells treated with different groups.

Notes: (A) Control, (B) cells treated with virus, and (C) cells treated with virus + Se@AM at $24 \mathrm{~h}$.

Abbreviations: AM, amantadine; MDCK, Madin-Darby Canine Kidney; Se@AM, AM-modified SeNPs; SeNPs, selenium nanoparticles; TEM, transmission electron microscopy; $\mathrm{N}$, nucleus; $\mathrm{M}$, mitochondria; Mv, microvilli. 

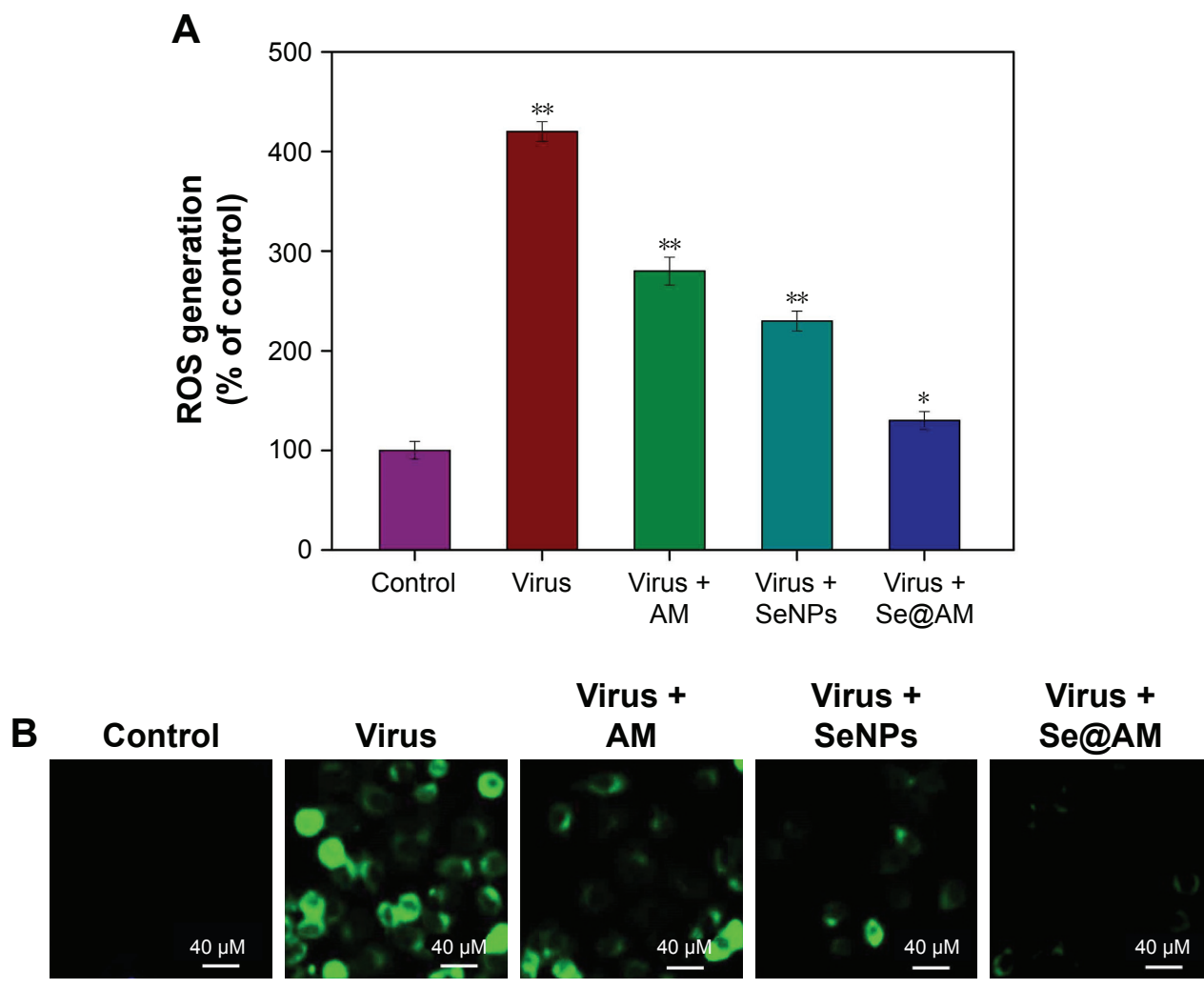

Figure I I ROS overproduction induced by Se@AM in HINI infection of MDCK cells.

Notes: (A) ROS levels were detected by DCF fluorescence intensity. (B) HINI infection of MDCK cells preincubated with $10 \mu M$ DCF for 30 min and then treated with

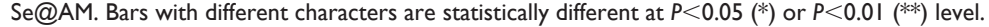

Abbreviations: AM, amantadine; DCF, 2',7'-dichlorofluorescein; MDCK, Madin-Darby Canine Kidney; ROS, reactive oxygen species; Se@AM, AM-modified SeNPs; SeNPs, selenium nanoparticles.

A

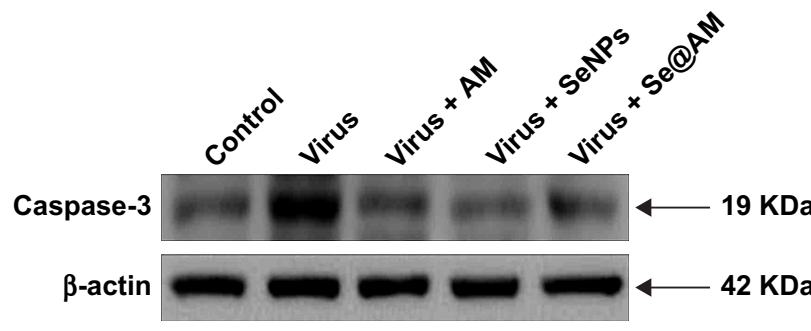

B

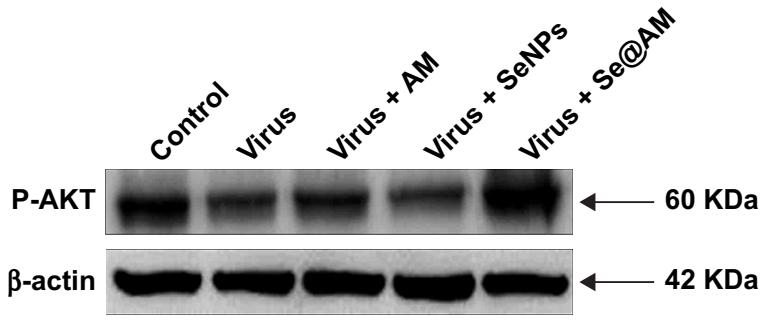

C

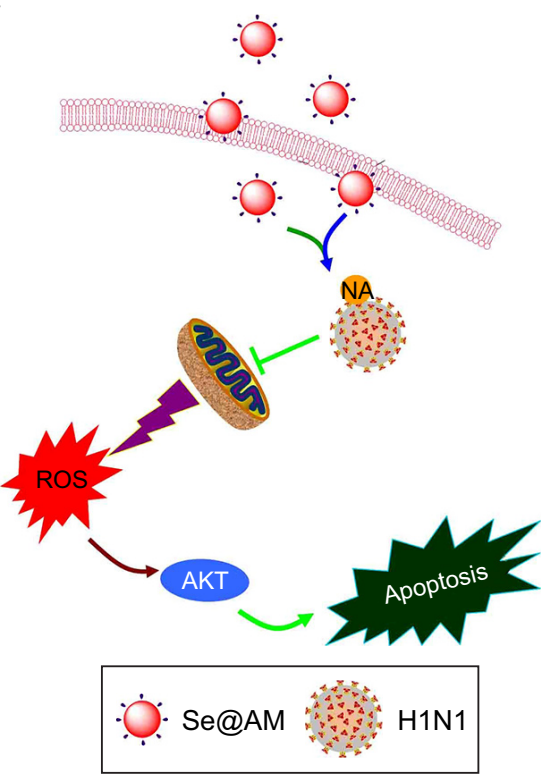

Figure 12 Intracellular apoptotic signaling pathways by Se@AM in HINI infection of MDCK cells.

Notes: (A) The protein expression of caspase-3. (B) Phosphorylation status expression levels of AKT pathways. (C) The main signaling pathway of ROS-mediated AKT signaling pathways. $\beta$-actin was used as loading control.

Abbreviations: AM, amantadine; MDCK, Madin-Darby Canine Kidney; ROS, reactive oxygen species; Se@AM, AM-modified SeNPs; SeNPs, selenium nanoparticles; NA, neuraminidase. 


\section{Acknowledgments}

This work was supported by the Technology Planning Project of Guangzhou (201804010183), Medical Scientific Research Foundation of Guangdong Province (A2018306), Medical Scientific Research Foundation of Guangdong Province (A2018289), The Technology Planning Project of Guangdong Province (2014A020212697), the Technology Planning Project of Guangzhou (201607010120), Guangzhou medical health science and technology project (20181A010022), Science and Technology Project of Guangzhou (201707010014), and National Natural Science Foundation of China (81600399).

\section{Disclosure}

The authors report no conflicts of interest in this work.

\section{References}

1. Li Y, Lin Z, Zhao M, et al. Silver nanoparticle based codelivery of oseltamivir to inhibit the activity of the H1N1 influenza virus through ROS-mediated signaling pathways. ACS Appl Mater Interfaces. 2016;8(37):24385-24393.

2. Wang CZ, Han HH, Tang XY, et al. Sialylglycan-assembled supra-dots for ratiometric probing and blocking of human-infecting influenza viruses. ACS Appl Mater Interfaces. 2017;9(30):25164-25170.

3. Yang M, Sunderland K, Mao C. Virus-derived peptides for clinical applications. Chem Rev. 2017;117(15):10377-10402.

4. Li YH, Lin ZF, Zhao MQ, et al. Reversal of H1N1 influenza virusinduced apoptosis by silver nanoparticles functionalized with amantadine. RSC Adv. 2016;6(92):89679-89686.

5. Li Y, Lin Z, Guo M, et al. Inhibitory activity of selenium nanoparticles functionalized with oseltamivir on $\mathrm{H} 1 \mathrm{~N} 1$ influenza virus. Int $J$ Nanomedicine. 2017;12:5733-5743.

6. Jung JH, Park BH, Oh SJ, Choi G, Seo TS. Integration of reverse transcriptase loop-mediated isothermal amplification with an immunochromatographic strip on a centrifugal microdevice for influenza A virus identification. Lab Chip. 2015;15(3):718-725.

7. Loveday EK, Diederich S, Pasick J, Jean F. Human microRNA-24 modulates highly pathogenic avian-origin $\mathrm{H} 5 \mathrm{~N} 1$ influenza A virus infection in A549 cells by targeting secretory pathway furin. $J$ Gen Virol. 2015;96(Pt 1):30-39.

8. Londrigan SL, Short KR, Ma J, et al. Infection of mouse macrophages by seasonal influenza viruses can be restricted at the level of virus entry and at a late stage in the virus life cycle. J Virol. 2015;89(24):12319-12329.

9. Liu Y, Zhang L, Wei W, et al. Colorimetric detection of influenza A virus using antibody-functionalized gold nanoparticles. Analyst. 2015; 140(12):3989-3995.

10. Hai W, Goda T, Takeuchi H, et al. Specific recognition of human influenza virus with PEDOT bearing sialic acid-terminated trisaccharides ACS Appl Mater Interfaces. 2017;9(16):14162-14170.

11. Lin Z, Li Y, Guo M, et al. The inhibition of H1N1 influenza virusinduced apoptosis by silver nanoparticles functionalized with zanamivir. RSC Adv. 2017;7(2):742-750.

12. Lin Z, Li Y, Guo M, et al. Inhibition of H1N1 influenza virus by selenium nanoparticles loaded with zanamivir through p38 and JNK signaling pathways. RSC Adv. 2017;7(56):35290-35296.

13. Chen Q, Guo Y. Influenza viral hemagglutinin peptide inhibits influenza viral entry by shielding the host receptor. ACS Infect Dis. 2016;2(3):187-193.

14. Gleed ML, Busath DD. Why bound amantadine fails to inhibit proton conductance according to simulations of the drug-resistant influenza $\mathrm{A}$ M2 (S31N). J Phys Chem B. 2015;119(3):1225-1231.
15. Gleed ML, Ioannidis H, Kolocouris A, Busath DD. Resistance-mutation (N31) effects on drug orientation and channel hydration in amantadinebound influenza A M2. J Phys Chem B. 2015;119(35):11548-11559.

16. Rey-Carrizo M, Barniol-Xicota M, Ma C, et al. Easily accessible polycyclic amines that inhibit the wild-type and amantadine-resistant mutants of the M2 channel of influenza A virus. J Med Chem. 2014;57(13): $5738-5747$.

17. Wu Y, Canturk B, Jo H, et al. Flipping in the pore: discovery of dual inhibitors that bind in different orientations to the wild-type versus the amantadine-resistant $531 \mathrm{~N}$ mutant of the influenza A virus M2 proton channel. J Am Chem Soc. 2014;136(52):17987-17995.

18. Durrant MG, Eggett DL, Busath DD. Investigation of a recent rise of dual amantadine-resistance mutations in the influenza A M2 sequence. BMC Genet. 2015;16(Suppl 2):S3.

19. Van Nguyen H, Nguyen HT, Le LT. Investigation of the free energy profiles of amantadine and rimantadine in the AM2 binding pocket. Eur Biophys J. 2016;45(1):63-70.

20. de Souza E Silva JM, Hanchuk TD, Santos MI, Kobarg J, Bajgelman MC, Cardoso MB. Viral inhibition mechanism mediated by surfacemodified silica nanoparticles. ACS Appl Mater Interfaces. 2016;8(26): 16564-16572.

21. Gustafsson S, Mihranyan A. Strategies for tailoring the pore-size distribution of virus retention filter papers. ACS Appl Mater Interfaces. 2016;8(22):13759-13767.

22. Li YH, Lin ZF, Xu TT, et al. Delivery of VP1 siRNA to inhibit the EV71 virus using functionalized silver nanoparticles through ROS-mediated signaling pathways. RSC Adv. 2017;7(3):1453-1463.

23. Tao W, Hurst BL, Shakya AK, et al. Consensus M2e peptide conjugated to gold nanoparticles confers protection against $\mathrm{H} 1 \mathrm{~N} 1, \mathrm{H} 3 \mathrm{~N} 2$ and $\mathrm{H} 5 \mathrm{~N} 1$ influenza A viruses. Antiviral Res. 2017;141:62-72.

24. Ye S, Shao K, Li Z, et al. Antiviral activity of graphene oxide: how sharp edged structure and charge matter. ACS Appl Mater Interfaces. 2015;7(38):21571-21579.

25. Vonnemann J, Sieben C, Wolff C, et al. Virus inhibition induced by polyvalent nanoparticles of different sizes. Nanoscale. 2014;6(4): 2353-2360.

26. Sokolova V, Westendorf AM, Buer J, Uberla K, Epple M. The potential of nanoparticles for the immunization against viral infections. J Mater Chem B. 2015;3(24):4767-4779.

27. Wang J, Zhu R, Gao B, et al. The enhanced immune response of hepatitis B virus DNA vaccine using SiO2@LDH nanoparticles as an adjuvant. Biomaterials. 2014;35(1):466-478.

28. Wang J, Liu Y, Xu K, et al. Broad-spectrum antiviral property of polyoxometalate localized on a cell surface. ACS Appl Mater Interfaces. 2014;6(12):9785-9789.

29. Barras A, Pagneux Q, Sane F, et al. High efficiency of functional carbon nanodots as entry inhibitors of herpes simplex virus type 1. ACS Appl Mater Interfaces. 2016;8(14):9004-9013.

30. Khanal M, Vausselin T, Barras A, et al. Phenylboronic-acid-modified nanoparticles: potential antiviral therapeutics. ACS Appl Mater Interfaces. 2013;5(23):12488-12498.

31. Ramya S, Shanmugasundaram T, Balagurunathan R. Biomedical potential of actinobacterially synthesized selenium nanoparticles with special reference to anti-biofilm, anti-oxidant, wound healing, cytotoxic and anti-viral activities. $J$ Trace Elem Med Biol. 2015;32: 30-39.

32. Stevanovic M, Filipovic N, Djurdjevic J, Lukic M, Milenkovic M, Boccaccini A. 45S5Bioglass (R)-based scaffolds coated with selenium nanoparticles or with poly(lactide-co-glycolide)/selenium particles: processing, evaluation and antibacterial activity. Colloids Sur B Biointerfaces. 2015;132:208-215.

33. Yang $\mathrm{Y}$, Xie Q, Zhao ZN, et al. Functionalized selenium nanosystem as radiation sensitizer of I-125 seeds for precise cancer therapy. ACS Appl Mater Interfaces. 2017;9(31):25857-25869. 
34. Jiang W, Fu Y, Yang F, et al. Gracilaria lemaneiformis polysaccharide as integrin-targeting surface decorator of selenium nanoparticles to achieve enhanced anticancer efficacy. ACS Appl Mater Interfaces. 2014; 6(16):13738-13748.

35. Huang Y, Luo Y, Zheng W, Chen T. Rational design of cancer-targeted BSA protein nanoparticles as radiosensitizer to overcome cancer radioresistance. ACS Appl Mater Interfaces. 2014;6(21):19217-19228.

36. Yu L, Sun L, Nan Y, Zhu LY. Protection from H1N1 influenza virus infections in mice by supplementation with selenium: a comparison with selenium-deficient mice. Biol Trace Elem Res. 2011;141(1-3):254-261.

37. Cheng Z, Zhi X, Sun G, et al. Sodium selenite suppresses hepatitis B virus transcription and replication in human hepatoma cell lines. J Med Virol. 2016;88(4):653-663.

38. Li Y, Lin Z, Zhao M, et al. Multifunctional selenium nanoparticles as carriers of HSP70 siRNA to induce apoptosis of HepG2 cells. Int $J$ Nanomedicine. 2016;11:3065-3076.

39. Li Y, Guo M, Lin Z, et al. Polyethylenimine-functionalized silver nanoparticle-based co-delivery of paclitaxel to induce HepG2 cell apoptosis. Int J Nanomedicine. 2016;11:6693-6702.

40. Zhu B, Li Y, Lin Z, et al. Silver nanoparticles induce HePG-2 cells apoptosis through ROS-mediated signaling pathways. Nanoscale Res Lett. 2016;11(1):98.

41. Liu W, Li X, Wong YS, et al. Selenium nanoparticles as a carrier of 5-fluorouracil to achieve anticancer synergism. ACS Nano. 2012;6(8): 6578-6591.

42. Li Y, Li X, Wong YS, et al. The reversal of cisplatin-induced nephrotoxicity by selenium nanoparticles functionalized with 11-mercapto1-undecanol by inhibition of ROS-mediated apoptosis. Biomaterials. 2011;32(34):9068-9076.
43. Xiang DX, Chen Q, Pang L, Zheng CL. Inhibitory effects of silver nanoparticles on H1N1 influenza A virus in vitro. J Virol Methods. 2011; 178(1-2):137-142.

44. Xiao S, Si L, Tian Z, et al. Pentacyclic triterpenes grafted on CD cores to interfere with influenza virus entry: a dramatic multivalent effect. Biomaterials. 2016;78:74-85.

45. Zhang Y, Li X, Huang Z, Zheng W, Fan C, Chen T. Enhancement of cell permeabilization apoptosis-inducing activity of selenium nanoparticles by ATP surface decoration. Nanomedicine. 2013;9(1):74-84.

46. Wu H, Li X, Liu W, et al. Surface decoration of selenium nanoparticles by mushroom polysaccharides-protein complexes to achieve enhanced cellular uptake and antiproliferative activity. J Mater Chem. 2012;22(19):9602-9610.

47. Li Y, Li X, Zheng W, Fan C, Zhang Y, Chen T. Functionalized selenium nanoparticles with nephroprotective activity, the important roles of ROS-mediated signaling pathways. J Mater Chem. 2012;22(19): 9602-9610.

48. Li X, Ma L, Zheng W, Chen T. Inhibition of islet amyloid polypeptide fibril formation by selenium-containing phycocyanin and prevention of beta cell apoptosis. Biomaterials. 2014;35(30):8596-8604.

49. Li JM, Wang YY, Zhao MX, et al. Multifunctional QD-based co-delivery of siRNA and doxorubicin to HeLa cells for reversal of multidrug resistance and real-time tracking. Biomaterials. 2012;33(9):2780-2790.

50. Fu X, Yang Y, Li X, et al. RGD peptide-conjugated selenium nanoparticles: antiangiogenesis by suppressing VEGF-VEGFR2-ERK/AKT pathway. Nanomedicine. 2016;12(6):1627-1639.

51. Xia Y, Lin Z, Li Y, et al. Targeted delivery of siRNA using RGDfCconjugated functionalized selenium nanoparticles for anticancer therapy. J Mater Chem B. 2017;5(33):6941-6952.
International Journal of Nanomedicine

\section{Publish your work in this journal}

The International Journal of Nanomedicine is an international, peerreviewed journal focusing on the application of nanotechnology in diagnostics, therapeutics, and drug delivery systems throughout the biomedical field. This journal is indexed on PubMed Central, MedLine, CAS, SciSearch ${ }^{\circledR}$, Current Contents ${ }^{\circledR} /$ Clinical Medicine,

\section{Dovepress}

Journal Citation Reports/Science Edition, EMBase, Scopus and the Elsevier Bibliographic databases. The manuscript management system is completely online and includes a very quick and fair peer-review system, which is all easy to use. Visit http://www.dovepress.com/ testimonials.php to read real quotes from published authors. 